\title{
Statins and Risk of New-Onset Diabetes Mellitus: is there a Rationale for Individualized Statin Therapy?
}

\author{
Eliano Pio Navarese - Anna Szczesniak • \\ Michalina Kolodziejczak • Bartosz Gorny • \\ Jacek Kubica · Harry Suryapranata
}

Published online: 31 October 2013

(c) The Author(s) 2013. This article is published with open access at Springerlink.com

\begin{abstract}
Statins (hydroxymethylglutaryl-coenzyme-A reductase inhibitors) are first-line agents for the management of hyperlipidemia in patients at high risk of cardiovascular (CV) events, and are the most commonly prescribed CV drugs worldwide. Although safe and generally well tolerated, there is growing evidence to suggest that statins are associated with an elevated occurrence of new-onset diabetes mellitus (DM). Recent experimental and clinical data have prompted the US Food and Drug Administration to add information to statin labels regarding the increased risk of development of type $2 \mathrm{DM}$. The main purpose of this review is to critically discuss the clinical evidence regarding the association of statin use with newonset DM, the CV benefit/risk ratio with statins, and the rationale for individualized statin therapy.
\end{abstract}

\section{Introduction}

Statins (hydroxymethylglutaryl-coenzyme-A [HMG-CoA] reductase inhibitors) are the most commonly prescribed cardiovascular (CV) drugs worldwide [1].

Although safe and generally well tolerated, emerging data have suggested that statins are associated with an increased rate of new-onset diabetes mellitus (DM). These

E. P. Navarese $(\square)$ - A. Szczesniak · M. Kolodziejczak ·

B. Gorny · J. Kubica

Department of Cardiology and Internal Medicine, Ludwik Rydygier Collegium Medicum, Nicolaus Copernicus University,

Skłodowskiej-Curie Street No 9, 8094 Bydgoszcz, Poland

e-mail: eliano.navarese@alice.it

H. Suryapranata

Department of Cardiology, UMC St Radboud, Nijmegen,

The Netherlands recent concerns have prompted the US Food and Drug Administration (FDA) to add information to statin labels about the increased risk of raised blood sugar levels and development of type 2 DM [2]. The present article aims to critically discuss (i) the mechanisms and clinical evidence linking statins to DM onset, (ii) the impact of different statin types or doses on DM, and (iii) the rationale of tailored statin therapy based on different clinical scenarios, including the patient's $\mathrm{CV}$ and metabolic risk profile.

\section{Statins and New-Onset Diabetes Mellitus (DM): is there a Link?}

Although the precise pathway responsible for DM onset with statin therapy is still unknown, there are several postulated mechanisms, some of which can be mentioned.

Statins can down-regulate the pancreatic $\beta$-cell function and insulin secretion via inhibition of glucose-induced $\mathrm{Ca}^{2+}$ signaling pathways [3].

Insulin release may also be impaired by the decreased amount of adenosine triphosphate (ATP), a result of statin suppression of the ubiquinone biosynthesis [4], which ultimately causes delayed production of ATP. It has also been hypothesized that statins may promote $\beta$-cell apoptosis, enhancing nitric oxide production by the endothelium [5]. Even though statins do not exert a class effect on insulin sensitivity, some inter-class differences have been observed.

Another suggested pathway influencing insulin sensitivity in statin-treated patients is the impact on insulinresponsive glucose transporter type (GLUT)-4. The inhibition of HMG-CoA reductase promoted by statins has a suppressing effect on isoprenoids synthesis, in turn resulting in decreased GLUT-4 expression and eventually to 
impaired glucose transport. Two studies [6, 7] showed that this mechanism is distinctive for atorvastatin and lovastatin; in contrast, the depression of adipocyte maturation was not reported with pravastatin intake. A further proposed mechanism lies in the effect on the adiponectin metabolism. Adiponectin is a hormone that modulates some metabolic processes, including glucose regulation. Among its actions, it decreases gluconeogenesis and increases glucose uptake; high levels of adiponectin have been associated with a reduction in the risk of developing type 2 DM in a prospective study [8]. Simvastatin has been reported to significantly reduce adiponectin levels and insulin sensitivity in hypercholesterolemic patients [9].

It has also been hypothesized that lipophilic and hydrophilic statins have different effects on adiponectin and insulin resistance. Pravastatin, a hydrophilic statin, increases adiponectin levels and insulin sensitivity [10]. An experimental study recently performed by Koh and colleagues [11], found that rosuvastatin, which is more potent and less hydrophilic, than pravastatin is associated with adverse metabolic effects, including increases in insulin resistance and glycosylated hemoglobin levels. Conversely, pravastatin proved to be safe by decreasing these two parameters; in the current study, rosuvastatin also decreased plasma adiponectin levels.

\section{Statins and New-Onset DM}

\subsection{Recent Evidence}

Several recent randomized controlled trials (RCTs) have yielded conflicting results regarding the induction of DM by statins. The WOSCOPS (West of Scotland Coronary Prevention Study) trial showed that the incidence of DM was $30 \%$ lower in male patients receiving pravastatin $40 \mathrm{mg} /$ day than in those receiving placebo [12]. However, this was not observed with atorvastatin $10 \mathrm{mg} /$ day in the ASCOT-LLA (Anglo-Scandinavian Cardiac Outcomes Trial-Lipid-Lowering Arm) trial [13], nor with simvastatin $40 \mathrm{mg} /$ day in the HPS (Heart Protection Study) trial [14]. The JUPITER (Justification for the Use of Statins in Primary Prevention: An Intervention Trial Evaluating Rosuvastatin) trial [15], using rosuvastatin $20 \mathrm{mg} /$ day in patients with elevated levels of C-reactive protein (CRP), was stopped early when an interim analysis found a $44 \%$ lower incidence of the primary endpoint. However, during the study, there was a $26 \%$ higher incidence of DM.

Rajpathak et al. [16] performed a meta-analysis of five trials involving 51,619 participants, among whom 1,943 developed DM. A small but significant increase in DM risk was found: relative risk (RR) 1.13; $95 \%$ confidence interval (CI) 1.03-1.23. The authors concluded that this finding may be related to statin use. In their initial analysis, they excluded WOSCOPS, describing it as hypothesisgenerating; with the incorporation of the WOSCOPS trial, the increase in DM risk was no longer significant.

Sattar and colleagues [17], in a larger meta-analysis published in 2010, included the 13 major statin trials (91,140 patients); each trial had more than 1,000 participants and more than 1 year of follow-up. However, the longest follow-up did not reach 5 years, new DM was observed in 2,226 (4.89\%) of the statin recipients and in $2,052(4.5 \%)$ of the placebo recipients (odds ratio [OR] 1.09 ; $95 \%$ CI 1.02-1.17).

Two of the arguments called to critically discuss this evidence can be cited: (i) the single studies were not designed and powered to primarily address DM as an endpoint and maximum follow-up did not exceed 5 years; (ii) the definition of DM varied among the trials, often derived from non-standardized criteria, and new-onset DM was usually not rigorously screened for. Combining both these elements, it is possible to conclude that we may even have underestimated the dimension of the problem.

\subsection{Impact of Different Types and Doses of Statin}

In recent years, the question has been raised as to whether or not the type of statin and the intensity of dose contributes to the conflicting results observed in RCTs and meta-analyses.

Carter and colleagues [18] recently conducted a population-based study, showing in a real-world setting that, compared with pravastatin (the reference drug in all analyses), there was an increased risk of incident DM with atorvastatin (adjusted hazard ratio [HR] 1.22; $95 \%$ CI 1.15-1.29), rosuvastatin (HR 1.18, $95 \%$ CI 1.10-1.26), and simvastatin (HR 1.10, $95 \%$ CI 1.04-1.17). The authors stated that the risk associated with rosuvastatin may be relevant to the dose of the drug. However, after the rosuvastatin dose was reduced, the statistical outcome was nonsignificant, suggesting a potential impact of indication or prescription bias that it was not possible to exclude because of the observational nature of the study.

Moreover, a published meta-analysis of five randomized trials $(N=32,752)$ [19] found that the use of intensivedose statin therapy compared with moderate-dose statin therapy was associated with a higher incidence of newonset DM. In this paper, DM developed in 1,449 (8.8\%) of the intensive-therapy group and 1,300 (8.0\%) of the moderate-therapy group (OR 1.12, $95 \%$ CI 1.04-1.22). In contrast, incident CV disease occurred in 3,134 (19.1\%) of the intensive-therapy group and 3,550 $(21.7 \%)$ of the moderate-therapy group (OR $0.84,95 \%$ CI $0.75-0.94$ ). Therefore, there was a $0.8 \%$ absolute increase in DM cases on high-dose statins and a $2.6 \%$ absolute reduction in adverse $\mathrm{CV}$ events. 
Fig. 1 Individual OR with related $95 \%$ CrIs for new-onset DM comparing intensive (a) or moderate (b) statin doses and placebo. Adapted from Navarese et al. [20]. Atorv atorvastatin, $\mathrm{CrI}$ credible interval, $D M$ diabetes mellitus, $O R$ odds ratio, Prav pravastatin, Rosuv rosuvastatin, Simv simvastatin

\section{A First drug/Second drug}

OR $(95 \% \mathrm{Crl})$

Atorv 80mg vs Placebo

Prav $40 \mathrm{mg}$ vs Placebo

Rosuv 20mg vs Placebo

Simv 40mg vs Placebo

Atorv $80 \mathrm{mg}$ vs Prav $40 \mathrm{mg}$

Atorv $80 \mathrm{mg}$ vs Rosuv $20 \mathrm{mg}$

Atorv $80 \mathrm{mg}$ vs Simv $40 \mathrm{mg}$

Prav $40 \mathrm{mg}$ vs Rosuv $20 \mathrm{mg}$

Prav 40mg vs Simv 40mg

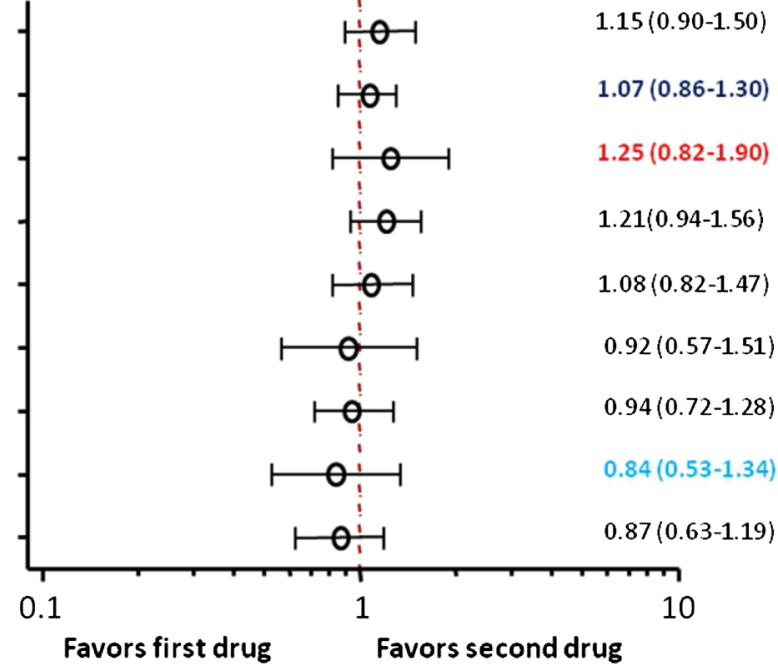

First drug/Second drug

B

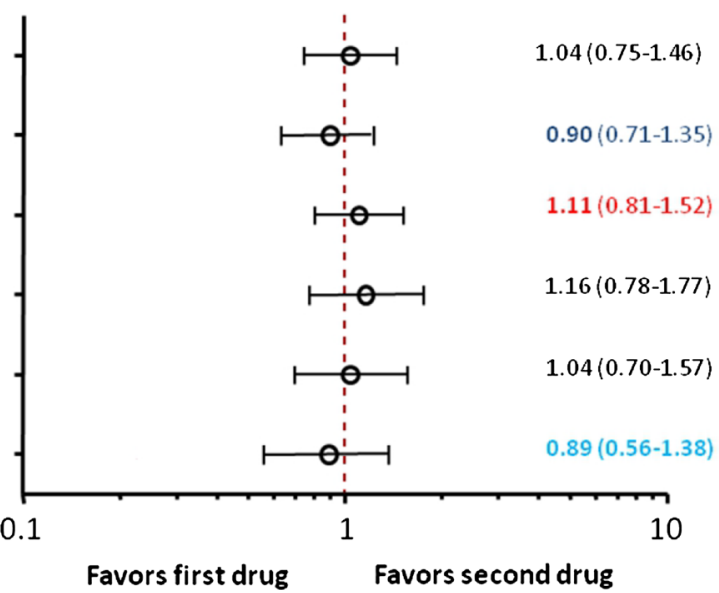

Recently, Navarese and colleagues [20] published the largest and most comprehensive meta-analysis so far, comparing rates of new-onset DM among different types and doses of statins. The main findings, derived from a population of 113,394 patients, were as follows: (i) there was a gradient in the risk for new-onset DM across different types and doses of statins (Fig. 1a); (ii) pravastatin therapy was numerically associated with the lowest OR of new-onset DM compared with placebo (OR 1.07, $95 \%$ credible interval 0.86-1.30); in contrast, treatment with rosuvastatin was numerically associated with a $25 \%$ increased risk of DM compared with placebo (OR 1.25, $95 \%$ credible interval $0.82-1.90$ ); (iii) the cumulative probabilities indicated that high-dose pravastatin had the highest probability of being the safest treatment in terms of new-onset DM, with rosuvastatin and simvastatin performing least well in this ranking; (iv) compared with placebo, high-dose pravastatin provided the most robust safety profile compared with the other high-dose statins; (v) the findings were confirmed with moderate doses of statins (Fig. 1b); and (vi) for each statin, increased doses carried a numerically higher risk for new-onset DM than moderate doses. As an additional datum, by meta-regression analysis, the risk for developing DM was not found to be influenced by the different abilities of statins to reduce cholesterol. On the basis of these findings, this meta-analysis supports the investigation of molecule-dependent mechanisms responsible for DM onset (Table 1).

\subsection{Clinical Benefits versus DM Risk with Statins}

CV disease (CVD) is the major cause of mortality and one of the most important causes of morbidity in the world. Owing to the major role of low-density lipoprotein (LDL) cholesterol as a modifiable risk factor, over the years, several international guidelines have recommended the 
Table 1 Effect of different statins on glucose metabolism

\begin{tabular}{|c|c|c|c|}
\hline Effect on glucose metabolism & Statin & Main observation & References \\
\hline \multirow[t]{2}{*}{ Decreased insulin secretion } & $\begin{array}{l}\text { Atorvastatin } \\
\text { Simvastatin }\end{array}$ & HMG-CoA inhibition/cytotoxicity & {$[30]$} \\
\hline & Simvastatin & Blocks L-type $\mathrm{Ca}^{2+}$ channels & [35] \\
\hline \multirow[t]{8}{*}{ Decreased insulin sensitivity } & Atorvastatin & Reduction in insulin sensitivity without reduction in insulin secretion & {$[31]$} \\
\hline & Atorvastatin & Inhibition of isoprenoid synthesis/GLUT-4 expression & {$[6,7]$} \\
\hline & Lovastatin & & {$[7,33]$} \\
\hline & Simvastatin & Decreased adiponectin secretion & {$[10]$} \\
\hline & Atorvastatin & & {$[32]$} \\
\hline & Rosuvastatin & & [36] \\
\hline & Rosuvastatin & HMG-CoA reductase inhibition via enhanced binding & [37] \\
\hline & & Insulin sensitization & [38] \\
\hline \multirow[t]{4}{*}{ Increased insulin sensitivity } & Atorvastatin & Induction of insulin sensitivity in lean and fatty rats & [33] \\
\hline & Pravastatin & Increased adiponectin secretion & {$[10,34,40,41]$} \\
\hline & Rosuvastatin & Normalizes elevated expression of PTP-1B & {$[38]$} \\
\hline & & Up-regulated expression of IRS-2, P-IRS-2, AKT, P-AKT, and GLUT4 & [39] \\
\hline \multirow[t]{4}{*}{ No effect on glucose metabolism } & Pravastatin & No effect on L-type $\mathrm{Ca}^{2+}$ channels & [35] \\
\hline & & No HMG-CoA inhibition/cytotoxicity & {$[30]$} \\
\hline & & Does not inhibit isoprenoid synthesis/GLUT-4 expression & [6] \\
\hline & & No effect on adiponectin secretion & {$[42,43]$} \\
\hline
\end{tabular}

$A K T$ protein kinase B, GLUT-4 glucose transporter type 4, HMG-CoA hydroxmethylglutaryl-coenzyme-A, IRS-2 insulin receptor substrate 2 , $P$-AKT phosphorylated protein kinase B, $P$-IRS-2 phosphorylated insulin receptor substrate $2, P T P-1 B$ protein phosphatase-1B

achievement of LDL goals in patients with different CV risk profiles (Table 2). Indeed, statins have largely been demonstrated in several landmark trials and meta-analyses [21-23] to be beneficial in secondary prevention of CV events and primary prevention in high-risk patients. Sattar and colleagues [17] estimated that statin treatment is associated with 5.4 fewer deaths from coronary heart disease and cases of nonfatal myocardial infarction per 255 patients treated over 4 years for each $1-\mathrm{mmol} / \mathrm{L}(39 \mathrm{mg} / \mathrm{dL})$ reduction in LDL cholesterol compared with controls. In contrast, there was a risk of developing one additional case of DM for 255 patients treated with statins. In the metaanalysis by Preiss et al. [19], 6.5 CV events were prevented in the intensive-dose statin group per 1,000 patient-years; this in turn translates into a number needed to treat (NNT) of 155 for CV events and a number needed to harm (NNH) of 498 for new-onset DM. In secondary prevention, benefits of statin therapy clearly outweigh DM risk.

Primary prevention in patients with no previous CVD is another important scenario not fully exploited in low-risk patients, for whom statin therapy is increasingly used for vascular prevention; indeed, there has been controversy as to whether the absolute benefit of treatment outweighs the risk of developing DM.

Importantly, a meta-analysis by Taylor et al. [24] found that statins in the primary prevention of CVD have no effects on significant reduction in all-cause mortality; this meta-analysis showed that a mortality relative risk reduction (RRR) of $17 \%$ was observed with statin treatment. However, they concluded that there is not enough evidence to recommend the widespread use of statins in the primary prevention of heart disease. The authors of this meta-analysis noticed that the absolute benefits were rather small1,000 people have to be treated for 1 year to prevent one death. The advantages of statin therapy therefore may become very small when used among people at low absolute risk, and a higher NNT to gain some benefit. Therefore, it is still uncertain where exactly the point lies beyond which the beneficial and protective $\mathrm{CV}$ actions of statins begin to outweigh the diabetogenic risk in primary prevention. The most recent individual-data meta-analysis of CTT (Cholesterol Treatment Trialists) Collaborators [25] states that even patients with low risk for CV events gain benefit from cholesterol-lowering treatment. In their study, each $1 \mathrm{mmol} / \mathrm{L}$ reduction in LDL cholesterol produced an absolute reduction in major vascular events of about 11 per 1,000 patients treated over 5 years. Intriguingly, age, sex, baseline LDL cholesterol, previous vascular disease, and vascular and all-cause mortality had little impact on the volume of major vascular event risk reduction.

In primary prevention with statins, the magnitude of the increased risk of incident DM is estimated to be $>50$-fold smaller than the absolute $\mathrm{CV}$ benefit: approximately 0.2 per 
Table 2 Guidelines on low-density lipoprotein goal with regards to cardiovascular risk

\begin{tabular}{|c|c|c|c|}
\hline Guidelines & Year & Risk category & LDL goal (mg/dL) \\
\hline \multirow[t]{5}{*}{ NCEP ATP III } & \multirow[t]{5}{*}{2004} & $\begin{array}{l}\text { High risk: CHD or CHD risk equivalent (e.g., DM or 10-year FRS } \\
>20 \% \text { ) }\end{array}$ & $\begin{array}{l}<100 \\
<70 \text { optional }\end{array}$ \\
\hline & & \multirow[t]{2}{*}{ Moderately high risk: $\geq 2$ risk factors (10-year FRS $10-20 \%$ ) } & $<130$ \\
\hline & & & $<100$ optional \\
\hline & & Moderate risk: $\geq 2$ risk factors $(10$-year FRS $<10 \%)$ & $<130$ \\
\hline & & Low risk: 1 or no risk factor & $<160$ \\
\hline \multirow{2}{*}{$\begin{array}{l}\text { ADA/ACC Consensus } \\
\text { Report }\end{array}$} & \multirow[t]{2}{*}{2008} & Highest risk: CVD or diabetes plus additional major CVD risk factors & $<70$ \\
\hline & & $\begin{array}{l}\text { High risk: No DM or known CVD but } \geq 2 \text { major CVD risk factors, or } \\
\text { DM but no other major CVD risk factors }\end{array}$ & $<100$ \\
\hline \multirow{2}{*}{$\begin{array}{l}\text { AHA/ACCF Guideline } \\
\text { on Secondary } \\
\text { Prevention }\end{array}$} & \multirow[t]{2}{*}{2011} & CHD or other atherosclerotic vascular disease & $\begin{array}{l}\geq 30 \% \text { reduction } \\
<100\end{array}$ \\
\hline & & CHD at very high risk & $<70$ reasonable \\
\hline \multirow[t]{2}{*}{$\begin{array}{l}\text { NLA Expert Panel on } \\
\text { FH Clinical Guidance }\end{array}$} & \multirow[t]{2}{*}{2011} & $\begin{array}{l}\text { Adults (aged } \geq 20 \text { years) with FHc and LDL-C } \geq 190 \mathrm{mg} / \mathrm{dL} \text { or non- } \\
\text { HDL-C } \geq 220 \mathrm{mg} / \mathrm{dL}\end{array}$ & $\geq 50 \%$ reduction \\
\hline & & $\begin{array}{l}\text { Children (aged } \geq 8 \text { years) with FHc and LDL-C } \geq 190 \mathrm{mg} / \mathrm{dL} \text { or non- } \\
\text { HDL-C } \geq 220 \mathrm{mg} / \mathrm{dL}\end{array}$ & $\begin{array}{l}\geq 50 \% \text { reduction } \\
\text { or }<130\end{array}$ \\
\hline \multirow[t]{4}{*}{ ESC/EAS } & \multirow[t]{4}{*}{2011} & \multirow{2}{*}{$\begin{array}{l}\text { Very high CV risk (established CVD, DM type } 2, \mathrm{DM} \text { type } 1 \text { with organ } \\
\text { damage, moderate to severe CKD or SCORE level } \geq 10 \% \text { ) }\end{array}$} & $<70$ \\
\hline & & & $\begin{array}{l}\text { And/or } \geq 50 \% \text { reduction, when } \\
\text { the target level can not be } \\
\text { reached }\end{array}$ \\
\hline & & $\begin{array}{l}\text { High CV risk (markedly elevated single risk factors, a SCORE level } \geq 5 \\
\text { to }<10 \% \text { ) }\end{array}$ & $<100$ \\
\hline & & Moderate risk (SCORE level $>1$ to $\leq 5 \%)$ & $<115$ \\
\hline \multirow[t]{5}{*}{ AACE } & \multirow[t]{5}{*}{2012} & $\begin{array}{l}\text { Very high risk established or recent hospitalization for coronary, carotid } \\
\text { or peripheral vascular disease; DM with } \geq 1 \text { additional risk factor(s) }\end{array}$ & $<70$ \\
\hline & & $\begin{array}{l}\text { High risk } \geq 2 \text { major risk factors and FRS }>20 \% ; \text { CHD risk equivalent } \\
\text { (carotid artery disease, abdominal aortic aneurysm, peripheral arterial } \\
\text { disease, DM) }\end{array}$ & $<100$ \\
\hline & & Moderately high risk $\geq 2$ major risk factors and FRS $10-20 \%$ & $<130$ \\
\hline & & Moderate risk $\geq 2$ major risk factors and FRS $<10 \%$ & $<130$ \\
\hline & & Low risk $\leq 1$ risk factor & $<160$ \\
\hline \multirow[t]{2}{*}{ ADA } & \multirow[t]{2}{*}{2013} & Individuals with DM and without overt CVD & $<100$ \\
\hline & & Individuals with DM and with overt CVD & $<70$ \\
\hline
\end{tabular}

AACE American Association of Clinical Endocrinologists, ADA/ACC American Diabetes Association/American College of Cardiology, AHA/ $A C C F$ American Heart Association/American College of Cardiology Foundation, $C H D$ coronary heart disease, $C K D$ chronic kidney disease, $C V$ cardiovascular, CVD CV disease, DM diabetes mellitus, EAS European Atherosclerosis Society, ESC European Society of Cardiology, FH familial hypercholesterolemia, FRS Framingham risk score, $H D L-C$ high-density lipoprotein cholesterol, $L D L$ - $C$ low-density lipoprotein cholesterol, NCEP ATP National Cholesterol Education Program Adult Treatment Panel, NLA National Lipid Association

1,000 individuals develop DM and 11 major CV events are prevented over a 5-year period. However, even in the lowest-risk group studied, the average baseline LDL cholesterol level was greater than $130 \mathrm{mg} / \mathrm{dL}$. Additionally, among the low-risk population, no significant benefit was observed with statin therapy with respect to CV mortality as a single endpoint; these points make it reasonable to be more cautious when treating these patients with statins. Therefore, any decision to use statins in primary prevention should be made in light of the assessment of the patient's overall CV risk and metabolic profile.

\subsection{Rationale for Tailored Statin Therapy}

To address the rationale for tailored statin therapy is crucial to underline the definition of tailored therapy; this is a strategy aimed to provide the right drug, the right dose, to the right patient and in the right time.

What is the rationale for individualized statin therapy? Different arguments are in favor of a more balanced tailored statin therapy based on clinical judgments, the patient's CV and metabolic risk profile, and the type and dose of statin used. 
Fig. 2 Individualized algorithm of treatment with statins, based on clinical scenario and patient's risk profile. $A C S$ acute coronary syndrome, $C A D$ coronary artery disease

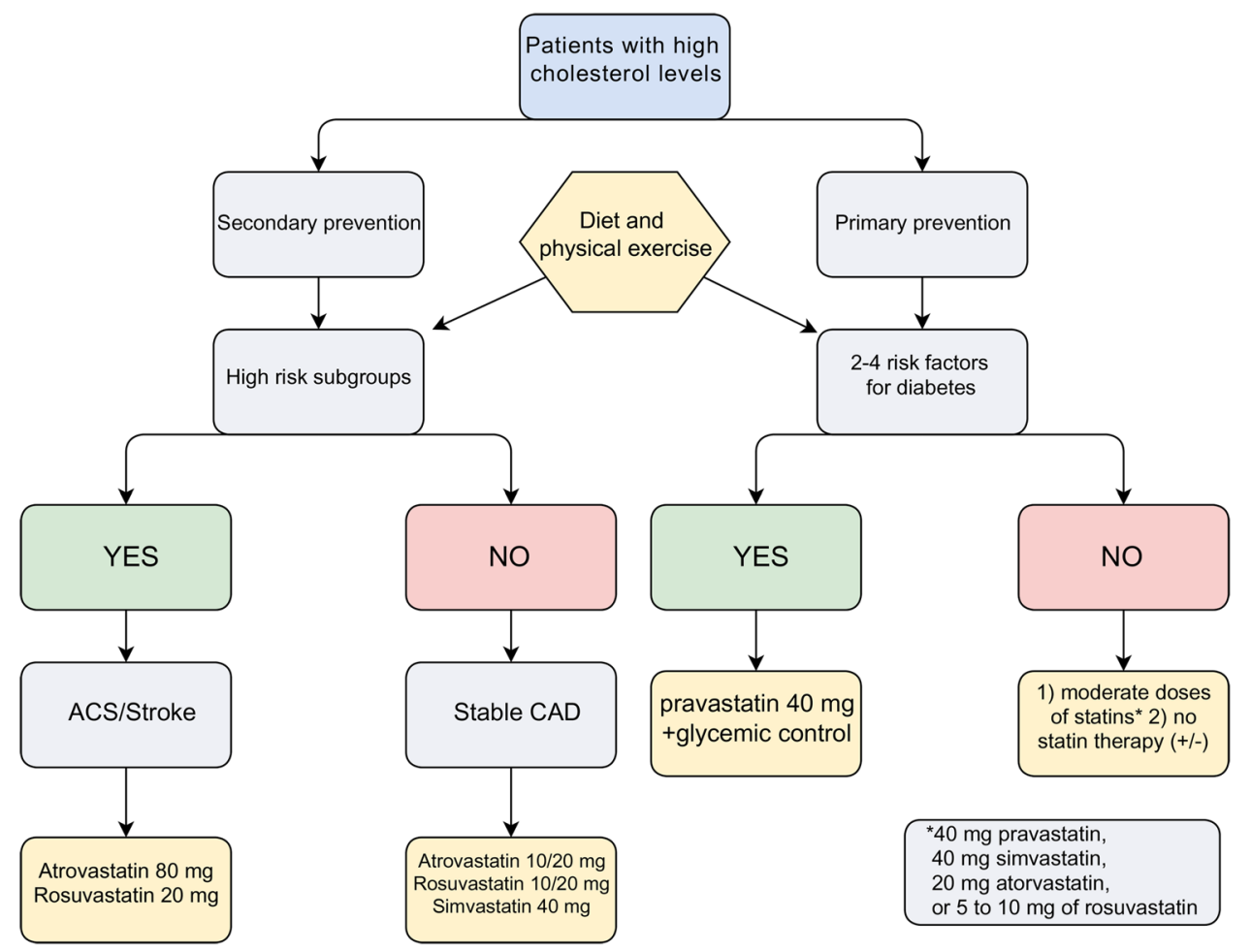

With regard to clinical setting and the patient's risk profile, as discussed previously, the benefit/risk assessment should be individualized based on the clinical scenario (primary/secondary prevention). In secondary prevention, the benefits of statin therapy clearly outweigh the risks of DM.

In primary prevention of low-risk patients, the cost effectiveness of such a strategy is less clear and has to be balanced against the risk of 'overmedicating' the general population.

A recent study [26] compared the incidence of newonset DM with CV risk reduction among 15,056 patients with coronary heart disease or a history of myocardial infarction but without DM at baseline in the TNT (Treating to New Targets) IDEAL (Incremental Decrease in Endpoints Through Aggressive Lipid Lowering) studies. Patients in these trials were randomly assigned to high- or low-dose statin $(80 \mathrm{mg}$ atorvastatin vs. $10 \mathrm{mg}$ atorvastatin or $20-40 \mathrm{mg}$ simvastatin). In particular, the investigators looked for differences in patients with $0-1$ risk factors for new-onset DM at baseline compared with those who had 2-4 risk factors (i.e., fasting blood glucose $>100 \mathrm{mg} / \mathrm{dL}$, history of hypertension, body mass index $>30 \mathrm{~kg} / \mathrm{m}^{2}$, and fasting triglycerides).

Among the patients with 0-1 risk factors at baseline, DM developed in 142 of 4,407 patients in the high-statin dose group and in 148 of 4,418 patients in the low-dose groups. Meanwhile, CV events were significantly lower in the high-dose group. Among the patients with 2-4 risk factors, DM developed in 448 of 3,128 patients in the highdose group and in 368 of 3,103 patients in the lower-dose groups. However, the risk for CV events was $18 \%$ lower in the high-dose group. The main finding of this analysis was that the increase in risk of DM was largest in patients who also received the largest risk reduction for $\mathrm{CV}$ events with statin therapy. However, it must be noted that the patients enrolled in the trials were in a 'secondary prevention' setting, already presenting at baseline with coronary artery disease and/or previous myocardial infarction. Importantly, the current study also suggests an increased risk of developing DM for patients who are at high metabolic risk.

Within this framework, tailoring therapy based on the specific type and dose of statin might play a crucial role; different types and doses of statin vary in their power to reduce cholesterol as well as in their 'diabetogenic' potential.

Physicians should now be aware that there is a gradient in the risk of new-onset DM across different types and doses of statins. Identifying patients who would benefit more from less diabetogenic statin types or regimens could help optimize the treatment by providing the highest benefit achievable while reducing the number of patients developing DM under statin therapy.

Based on our findings, pravastatin could be the right match for hyperlipidemic patients at low CV risk. Indeed, despite its lower potential to lower LDL cholesterol concentrations, it seems to be the least diabetogenic statin currently available on the market. Although marginalized 
by newer, more powerful, and more advertised statins, pravastatin could serve as a valuable alternative, especially for patients with a predisposition for DM; the lower price of the drug (being now available as a generic) could also increase the cost effectiveness of medicating the low-risk population.

Nevertheless, it is crucial to remember that statins cannot account for all new cases of DM diagnosed during hypolipidemic therapy. Waters et al. [26] support this concept, showing that the hazard of developing new-onset DM is directly connected with already existing DM risk factors.

\subsection{Proposed Individualized Algorithm of Treatment}

We propose an individualized and simplified algorithm of statin treatment based on the current evidence (Fig. 2). The present algorithm does not aim to replace any guideline recommendations based on cholesterol levels; the focus of this scheme is the clinical scenario and patient risk that can orient towards the choice of a specific type and dose of statin.

The benefits of statins outweigh the increased risk of DM in people with CVD or at moderate to high risk of CVD. In such patients, a powerful statin like rosuvastatin or atorvastatin should be recommended. Individuals with high CV risk (10-year risk $>20 \%$, according to the Framingham risk score) or existing CVD should receive statin therapy as indicated. Individuals with moderate $\mathrm{CV}$ risk ( $\geq 2$ risk factors, 10 -year risk $\leq 20 \%$ ) should also be prescribed a statin. In high-risk subgroups such as after an episode of acute coronary syndrome (ACS), high doses of a powerful statin like rosuvastatin or atorvastatin are highly recommended.

The potentially raised DM risk exceeding benefits should be particularly considered in individuals with low CV risk (0-1 risk factors). Prior to initiation of statin therapy, screening for risk factors of DM and metabolic syndrome may help identify patients at high risk of DM requiring closer monitoring. According to the recent evidence, pravastatin can be the statin of choice in such populations. As discussed previously, there is thus far a lack of conclusive evidence in favor of statin administration in low-risk patients.

In the present algorithm, the patient population was divided into two treatment groups, according to the clinical setting at presentation (primary and secondary prevention). In the secondary prevention setting and high risk population, such as patients after ACS or stroke, we suggest, based on the current evidence, treatment with intensive doses of such a statin as atorvastatin $80 \mathrm{mg}$ [27, 28]. However, in the case of patients with stable coronary artery disease, lower doses such as atorvastatin 10-20 mg, rosuvastatin $10-20 \mathrm{mg}$, or simvastatin $40 \mathrm{mg}$ would be a reasonable option. In the primary prevention group, patients can be stratified according to the number of DM risk factors; in the higher risk subset, constant glycemic control is advised, together with statin therapy at moderate doses, such as pravastatin $40 \mathrm{mg}$ [12]. The last analysed category is that of patients with one or no risk factors for new-onset DM; moderate doses might be used in such patients. An alternative option is to only monitor glucose more closely, avoiding the prescription of statins, although there is less robust evidence in this regard. Further RCTs are certainly needed to definitively confirm the clinical impact of tailored statin treatment based on risk scenario and the patient's risk profile.

\subsection{Future Research}

As recommendations for the future, it is essential to conduct long-term prospective RCTs and cost-effectiveness analyses to address the benefit/risk ratio of statins, especially in the field of primary prevention. Indeed, the cost effectiveness of such a strategy is unclear in these low-risk patients and has to be balanced against the risk of 'overmedicating' the general population. Additional studies are also warranted to determine the mechanism of statininduced DM, the time to the onset of DM, and the degree of hyperglycemia. Finally, the question of why statins cause DM must be answered. A genomic stratification might further identify patients at risk for this important and chronic side effect, similar to the variability in treatment response found based on the pharmacogenomic profile [29].

\section{Conclusions}

Medicine is a dynamic field. According to emerging data on statin therapy, 'one size does not fit all' with respect to DM: each statin is associated with a specific DM risk profile. A potential tailored statin treatment based on the patient's $\mathrm{CV}$ and metabolic risk profile might emerge as the safest therapeutic approach. Future trials with adequate follow-up of more than 5 years and designed to assess the benefit/risk ratio of a specific statin will further refine the basis of this strategy.

Acknowledgments The present contribution is a project of Systematic Investigation and Research on Interventions and Outcomes (SIRIO)-MEDICINE, a selected group of senior scientists and fellows collaborating worldwide to pursue research and innovation in medicine (http://www.siriomedicine.com).

Conflict of interest The authors have no conflicts of interest to declare. 
Open Access This article is distributed under the terms of the Creative Commons Attribution Noncommercial License which permits any noncommercial use, distribution, and reproduction in any medium, provided the original author(s) and the source are credited.

\section{References}

1. Mills E, Wu P, Chong G, et al. Efficacy and safety of statin treatment for cardiovascular disease: a network meta-analysis of 170255 patients from 76 randomized trials. Q J Med. 2011;104:109-24.

2. United States Food and Drug Administration. FDA expands advice on statin risks. http://www.fda.gov/ForConsumers/ ConsumerUpdates/ucm293330.htm. Accessed 24 Nov 2012.

3. Koh K, Quon M, Han S. Differential metabolic effects of pravastatin and simvastatin in hypercholesterolemic patients. Atherosclerosis. 2009;204(2):483-90.

4. Mabuchi H, Higashikata T, Kawashiri M, Katsuda S, Mizuno M, Nohara A, Inazu A, Koizumi J, Kobayashi J. Reduction of serum ubiquinol-10 and ubiquinone-10 levels by atorvastatin in hypercholesterolemic patients. J Atheroscler Thromb. 2005;12:111-9.

5. Nakata M, Uto N, Maruyama I, Yada T. Nitric oxide induces apoptosis via $\mathrm{Ca}^{2+}$-dependent processes in the pancreatic betacell line MIN6. Cell Struct Funct. 1999;24:451-5.

6. Nakata M, Nagasaka S, Kusaka I, Matsuoka H, Ishibashi S, Yada $\mathrm{T}$. Effects of statins on the adipocyte maturation and expression of glucose transporter 4 (SLC2A4): implications in glycaemic control. Diabetologia. 2006;49:1881-92.

7. Chamberlain LH. Inhibition of isoprenoid biosynthesis causes insulin resistance in 3T3-L1 adipocytes. FEBS Lett. 2001;507: 357-61.

8. Spranger J, Kroke A, Mohlig M, Bergmann MM, Ristow M, Boeing $\mathrm{H}$, Pfeiffer AF. Adiponectin and protection against type 2 diabetes mellitus. Lancet. 2003;361:226-8.

9. Koh KK, Quon MJ, Han SH, Lee Y, Ahn JY, Kim SJ, Koh Y, Shin EK. Simvastatin improves flow-mediated dilation but reduces adiponectin levels and insulin sensitivity in hypercholesterolemic patients. Diabetes Care. 2008;31:776-82.

10. Koh KK, Quon MJ, Han SH, Lee Y, Kim SJ, Park JB, Shin EK. Differential metabolic effects of pravastatin and simvastatin in hypercholesterolemic patients. Atherosclerosis. 2009;204: 483-90.

11. Koh KK, Quon MJ, Sakuma I, Han SH, Choi H, Lee K, Shin EK. Differential metabolic effects of rosuvastatin and pravastatin in hypercholesterolemic patients. Int J Cardiol. 2013;166:509-15.

12. Freeman DJ, Norrie J, Sattar N, Neely RD, Cobbe SM, Ford I, Isles C, Lorimer AR, Macfarlane PW, McKillop JH, Packard CJ, Shepherd J, Gaw A. Pravastatin and the development of diabetes mellitus: evidence for a protective treatment effect in the west of Scotland coronary prevention study. Circulation. 2001;103: 357-62.

13. Sever PS, Dahlof B, Poulter NR, Wedel H, Beevers G, Caulfield M, Collins R, Kjeldsen SE, Kristinsson A, McInnes GT, Mehlsen J, Nieminen M, O'Brien E, Ostergren J. Prevention of coronary and stroke events with atorvastatin in hypertensive patients who have average or lower-than-average cholesterol concentrations, in the Anglo-Scandinavian Cardiac Outcomes Trial-Lipid Lowering Arm (ASCOT-LLA): a multicentre randomised controlled trial. Lancet. 2003;361:1149-58.

14. Collins R, Armitage J, Parish S, Sleigh P, Peto R. MRC/BHF heart protection study of cholesterol-lowering with simvastatin in 5963 people with diabetes: a randomised placebo-controlled trial. Lancet. 2003;361:2005-16.
15. Ridker PM, Danielson E, Fonseca FA, Genest J, Gotto AM Jr, Kastelein JJ, Koenig W, Libby P, Lorenzatti AJ, MacFadyen JG, Nordestgaard BG, Shepherd J, Willerson JT, Glynn RJ. Rosuvastatin to prevent vascular events in men and women with elevated C-reactive protein. N Engl J Med. 2008;359:2195-207.

16. Rajpathak SN, Kumbhani DJ, Crandall J, Barzilai N, Alderman M, Ridker PM. Statin therapy and risk of developing type 2 diabetes: a meta-analysis. Diabetes Care. 2009;32:1924-9.

17. Sattar N, Preiss D, Murray HM, Welsh P, Buckley BM, de Craen AJ, Seshasai SR, McMurray JJ, Freeman DJ, Jukema JW, Macfarlane PW, Packard CJ, Stott DJ, Westendorp RG, Shepherd J, Davis BR, Pressel SL, Marchioli R, Marfisi RM, Maggioni AP, Tavazzi L, Tognoni G, Kjekshus J, Pedersen TR, Cook TJ, Gotto AM, Clearfield MB, Downs JR, Nakamura H, Ohashi Y, Mizuno K, Ray KK, Ford I. Statins and risk of incident diabetes: a collaborative meta-analysis of randomised statin trials. Lancet. 2010;375:735-42.

18. Carter AA, Gomes T, Camacho X, Juurlink DN, Shah BR, Mamdani MM. Risk of incident diabetes among patients treated with statins: population based study. BMJ. 2013;346:f2610.

19. Preiss D, Seshasai SR, Welsh P, Murphy SA, Ho JE, Waters DD, DeMicco DA, Barter P, Cannon CP, Sabatine MS, Braunwald E, Kastelein JJ, de Lemos JA, Blazing MA, Pedersen TR, Tikkanen MJ, Sattar N, Ray KK. Risk of incident diabetes with intensivedose compared with moderate-dose statin therapy: a meta-analysis. JAMA. 2011;305:2556-64.

20. Navarese EP, Buffon A, Andreotti F, Kozinski M, Welton N, Fabiszak T, Caputo S, Grzesk G, Kubica A, Swiatkiewicz I, Sukiennik A, Kelm M, De Servi S, Kubica J. Meta-analysis of impact of different types and doses of statins on new-onset diabetes mellitus. Am J Cardiol. 2013;111:1123-30.

21. Prevention of $\mathrm{CV}$ events and death with pravastatin in patients with coronary heart disease and a broad range of initial cholesterol levels. The long-term intervention with pravastatin in ischaemic disease (lipid) study group. N Engl J Med. 1998;339: 1349-57.

22. Randomised trial of cholesterol lowering in 4444 patients with coronary heart disease: the scandinavian simvastatin survival study (4s). Lancet. 1994;344:1383-9.

23. Baigent C, Keech A, Kearney PM, Blackwell L, Buck G, Pollicino C, Kirby A, Sourjina T, Peto R, Collins R, Simes R. Efficacy and safety of cholesterol-lowering treatment: prospective metaanalysis of data from 90,056 participants in 14 randomised trials of statins. Lancet. 2005;366:1267-78.

24. Taylor F, Ward K, Moore TH, Burke M, Davey Smith G, Casas JP, Ebrahim S. Statins for the primary prevention of CV disease. Cochrane Database Syst Rev. 2011;(1):CD004816.

25. Mihaylova B, Emberson J, Blackwell L, Keech A, Simes J, Barnes EH, Voysey M, Gray A, Collins R, Baigent C. The effects of lowering LDL cholesterol with statin therapy in people at low risk of vascular disease: meta-analysis of individual data from 27 randomised trials. Lancet. 2012;380:581-90.

26. Waters DD, Ho JE, Boekholdt SM, DeMicco DA, Kastelein JJ, Messig M, Breazna A, Pedersen TR. CV event reduction versus new-onset diabetes during atorvastatin therapy: effect of baseline risk factors for diabetes. J Am Coll Cardiol. 2013;61:148-52.

27. Cannon CP, Braunwald E, McCabe CH, Rader DJ, Rouleau JL, Belder R, Joyal SV, Hill KA, Pfeffer MA, Skene AM, Pravastatin or Atorvastatin Evaluation and Infection Therapy-Thrombolysis in Myocardial Infarction 22 Investigators. Intensive versus moderate lipid lowering with statins after acute coronary syndromes. N Engl J Med. 2004;350:1495.

28. Amarenco P, Bogousslavsky J, Callahan A 3rd, Goldstein LB, Hennerici M, Rudolph AE, Sillesen H, Simunovic L, Szarek M, Welch KM, Zivin JA, Stroke Prevention by Aggressive Reduction in Cholesterol Levels (SPARCL) Investigators. High-dose 
atorvastatin after stroke or transient ischemic attack. N Engl J Med. 2006;355:549-59.

29. $\mathrm{Hu}$ M, Tomlinson B. Pharmacogenomics of lipid-lowering therapies. Pharmacogenomics. 2013;14:981-95.

30. Ishikawa $\mathrm{M}$, Okajima $\mathrm{F}$, Inoue $\mathrm{N}$, Motomura $\mathrm{K}$, Kato $\mathrm{T}$, Takahashi A, Oikawa S, Yamada N, Shimano H. Distinct effects of pravastatin, atorvastatin, and simvastatin on insulin secretion from a beta-cell line, MIN6 cells. J Atheroscler Thromb. 2006;13:329-35.

31. Koh K, Sakuma I, Quon M. Differential metabolic effects of distinct statins. Atherosclerosis. 2011;215:1-8.

32. Koh KK, Quon MJ, Han SH, Lee Y, Kim SJ, Shin EK. Atorvastatin causes insulin resistance and increases ambient glycemia in hypercholesterolemic patients. J Am Coll Cardiol. 2010;55: 1209-16.

33. Wong V, Stavar L, Szeto L, Uffelman K, Wang CH, Fantus IG, Lewis GF. Atorvastatin induces insulin sensitization in Zucker lean and fatty rats. Atherosclerosis. 2006;184:348-55.

34. Takagi T, Matsuda M, Abe M, Kobayashi H, Fukuhara A, Komuro R, Kihara S, Caslake MJ, McMahon A, Shepherd J, Funahashi T, Shimomura I. Effect of pravastatin on the development of diabetes and adiponectin production. Atherosclerosis. 2008;196:114-21.

35. Yada T, Nakata M, Shiraishi T, Kakei M. Inhibition by simvastatin, but not pravastatin, of glucose-induced cytosolic $\mathrm{Ca}^{2+}$ signalling and insulin secretion due to blockade of L-type $\mathrm{Ca}^{2+}$ channels in rat islet beta-cells. Br J Pharmacol. 1999;126: 1205-13.

36. Koh KK, Quon MJ, Sakuma I, Han SH, Choi H, Lee K, Shin EK. Differential metabolic effects of rosuvastatin and pravastatin in hypercholesterolemic patients. Int J Cardiol. 2013;20(166): 509-15.
37. Chong T, Naples M, Federico L, Taylor D, Smith GJ, Cheung $\mathrm{RC}$, Adeli K. Effect of rosuvastatin on hepatic production of apolipoprotein B-containing lipoproteins in an animal model of insulin resistance and metabolic dyslipidemia. Atherosclerosis. 2006; $185: 21-31$.

38. Naples M, Federico LM, Xu E, Nelken J, Adeli K. Effect of rosuvastatin on insulin sensitivity in an animal model of insulin resistance: evidence for statin-induced hepatic insulin sensitization. Atherosclerosis. 2008;198:94-103.

39. Guo H, Lv H, Tang W, Chi J, Liu L, Xu F, Ji Z, Zhai X, Peng F. Rosuvastatin may modulate insulin signaling and inhibit atherogenesis beyond its plasma cholesterol-lowering effect in insulinresistant mice. Cardiovasc Drugs Ther. 2012;26:375-82.

40. Sakamoto K, Sakamoto T, Ogawa H. The effect of 6 months of treatment with pravastatin on serum adiponectin concentrations in Japanese patients with coronary artery disease and hypercholesterolemia: a pilot study. Clin Ther. 2006;28:1012-21.

41. Sugiyama S, Fukushima H, Kugiyama K, et al. Pravastatin improved glucose metabolism associated with increasing plasma adiponectin in patients with impaired glucose tolerance and coronary artery disease. Atherosclerosis. 2007;194:e43-51.

42. Gannagé-Yared MH, Azar RR, Amm-Azar M, Khalifé S, Germanos-Haddad M, Neemtallah R, Halaby G. Pravastatin does not affect insulin sensitivity and adipocytokines levels in healthy nondiabetic patients. Metabolism. 2005;54:947-51.

43. Shetty GK, Economides PA, Horton ES, Mantzoros CS, Veves A. Circulating adiponectin and resistin levels in relation to metabolic factors, inflammatory markers, and vascular reactivity in diabetic patients and subjects at risk for diabetes. Diabetes Care. 2004;27:2450-7. 